\title{
Design of testing Method of Fuels Filling Measurement Instrument
}

\author{
Ratna Purwaningsih ${ }^{1}$, Susatyo Nugroho Widyo Pramono ${ }^{1}$, Farhan Atoilah ${ }^{1 a^{*}}$, Aan Aria \\ $\mathrm{Nanda}^{2}$, Azizah Dewi Suryaningsih ${ }^{3}$ \\ ${ }^{1}$ Department of Industrial Engineering, Faculty of Engineering, Diponegoro University, Semarang - \\ Indonesia \\ ${ }^{2}$ Department of Electrical Engineering, Faculty of Engineering, Diponegoro University, Semarang - \\ Indonesia \\ ${ }^{3}$ Department of Regional and Urban Planning, Faculty of Engineering, Diponegoro University, \\ Semarang - Indonesia
}

\begin{abstract}
In this paper we have proposed a technique as a testing method for the instrument of measuring the amount of fuel filled in motorbike fuel tank. The instrument used a fluid flow meter that can be used easily by consumers to check the accuracy of gas station filler gauge. The study aims to develop a prototype of fluid flow measurement devices and a digital reporting system through IoT. The research phase consists of designing a fluid flow equipment, designing a color detection device, and designing a reporting system with IoT. Reporting application uses the smartphone system as a display of measurement results from flow meters and color detectors. Testing the function of the accuracy of the flow sensor on the tool is done by using a calibration factor. The output of measurements are fuel volume discharge, type of fluid and the result are shown on smartphone which connected to the internet for its reporting system.
\end{abstract}

Keywords: instrument, testing method, fluid flow meter, digital reporting system.

\section{Introduction}

Now-a-days all fuel bunks having types of digital displays unit in order to display the value of fuel adding to the vehicle. But we don't know whether they adding accurate value or not [1]. Fraud at public fueling stations is found in many countries. This study aims to design a product measuring the volume of fuel which can later be used to check whether the fuel loaded in the vehicle tank is in accordance with the amount purchased. This tool utilizes the use of a water discharge sensor or commonly called a flow sensor, a fluid discharge measuring device used on a flow meter. This flow meter is connected to Android wirelessly to provide information to users. The use of android opens the potential for sending data online

${ }^{*}$ Corresponding author: farkhanatoillah@gmail.com 
so that the data collected can be used as a means of monitoring and evaluation to these fuel oil sales service providers.

The largest population of consumers who buy fuel in Indonesia is motorcycle users. In 2018 the number of motorbikes is 120 thousand out of 147 thousand of the total number of vehicles in Indonesia. Data from Indonesian Central Bureau of Statistics, the last 10 years shows that the number of motorbikes is around $81 \%$ of the total number of vehicles [2]. Then, the design of this instrument focused on motorcycle users as a potential market for a fuel filling measurement instrument.

The product concept was formulated based on the needs of consumers from the questionnaire to 300 respondents. The result of questionnaire data processing shows that majority of consumers are not aware of the fraud experienced and the absence of methods to prove the fraud. The research urgency is the measuring instrument as the output of the research has great benefits for the community, especially for the protection of consumers. Feed backs from the public in the form of data matching the volume of fuel that is filled with those paid will help create public accountability in fuel distribution by gas station. The reporting application developed is designed based on the Android system with the aim of comparing the amount of fuel that is filled into the tank with the data written on the purchase record. The digitally displays system report the level of fuel inside the tank by using flow meter and these sensors are interfaced with a development board-Arduino. Thus, it is an efficient system to detect the fuel volume in the fuel tank, to get instantaneous reading of fuel volume and to avoid petroleum thefts at the various petrol. Beside Liquid level measurement is necessary in Industrial automation and Industries and variety of filling process.

\section{Literature review}

The product development process consists of seven stages, starting with the customer identification stage, the interview process to map the needs of the customers is recommended to be recorded, the interview results grouped according to the similarity of needs and then assessed based on their level of importance. Before the final step of making a product, product ideas must be made to determine the final product and process specifications [3].

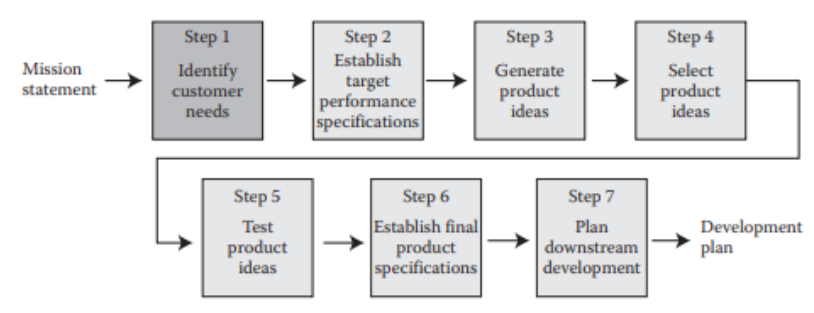

Fig 1. Product design step

Overall, the prototype instrument consists of propeller which functions as a flow meter to measure water flow, sensors that send data from the instrument to the processing unit, and the Android application as a display of the measurement results. Detection is done on two things, namely the volume of fuels that are loaded and on the type of fuels with a color sensor. Then there is an application in Android that can perform the reporting function by sending measurement results to the data receiver center [4]. Figure 1 shows the component of the instrument. 

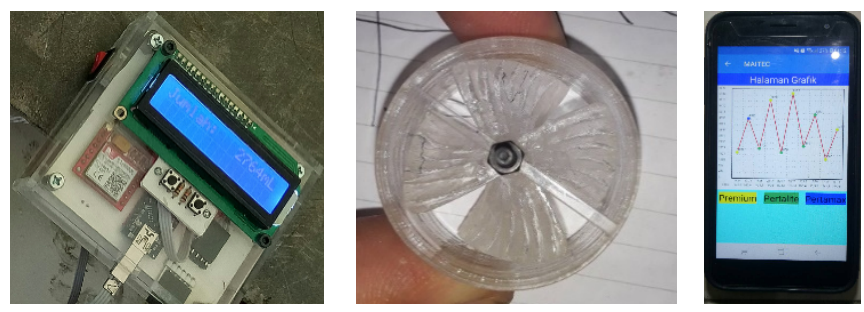

Fig 2. The component of the instrument.

\subsection{Flow Discharge Measurement}

A fluid discharge sensor or a flow sensor is a measuring device that mostly used on flow meters. The accuracy of measurements requires sensor calibration. The flow sensor type used is a mechanical flow sensor. This type of sensor has a rotor and a transducer hall-effect in it to detect the rotation of the rotor when fluid passes through it. The rotation will produce a digital pulse whose amount is proportional to the amount of fluid flowing through it [5]. The hall effect sensor measured the fluid discharge by calculating the pulse frequency $(\mathrm{Hz})$ multiplied by the calibration factor which will be added to the total amount of fuel [6]. Volume gauges can also be designed using Water Sensor Flow (WSF) which is controlled by Arduino Uno and the information is in Liquid Crystal Display or LCD [7].

Various type of methods for measuring liquid level using capacitive sensors, optical sensors methods, mechanical float to ultra-sound methods. Optical sensors, such as CCD cameras, can measure liquid level without having to contact the liquid by image processing [8]. In addition to using a flow meter, there is also a volume measuring device that uses a float type sensor like a car fuel gauge. A fuel gauge (or gas gauge) is an instrument used to indicate the level of fuel contained in a tank. The systems consist of two important circuitry that is for sensing and indication of fuel level. The sensing unit usually uses a float type sensor to measure fuel level while the indicator system measures the amount of electric current flowing through the sensing unit and indicates fuel level [9].

\subsection{Colour Detection}

Color detection uses TCS3200 which is a converter programmed to convert colors into frequencies composed of silicon photodiode configurations and current to frequency converters in a single monolithic CMOS IC component. The output of this sensor is a square wave frequency which is directly proportional to the light intensity (irradiance). Full-scale frequency outputs can be scaled by one of three values set via two input pin controls. Digital input and output directly connect to microcontrollers interface or other logic circuits [10].

TCS3200 has an array of photodiodes with 4 different filters. A photodiode is simply a semiconductor device that converts light into current. The sensor has red filter that sensitive to red wavelength, green filter that sensitive to green wavelength, blue filter that sensitive to blue wavelength and photodiodes that without filter, each of this filter have 16 photo-diode in it. Many uses of the TCS3200 Color Light Sensor one of which is the sensor was used to detect the color of the product Edge Banding in Laser Edge Banding Machine. Sensor Color TCS3200 is a programmable color light to frequency converter developed by TAOS (Texas Advanced Optoelectronic Solutions), TCS3200 is a programmable IC which is the way it works to convert light into color frequency [11]. 
By selectively choosing the photodiode filter's readings, sensor can detect the intensity of the different colors. The sensor has a current-to-frequency converter that converts the photodiodes' readings into a square wave with a frequency that is proportional to the light intensity of the chosen color. This frequency is then, read by the Arduino this is shown in the figure below. Arduino is an open source electronics prototyping platform based on flexible, easy-to-use hardware and software. It's intended for artists, designers, hobbyists and anyone interested in creating interactive objects or environments [12].

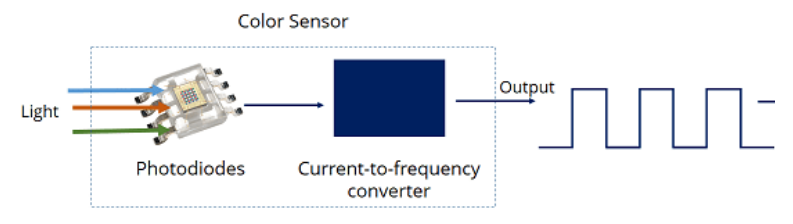

Fig 3. TCS3200 Colour Sensing Method

Color detection uses TCS3200 which is a converter programmed to convert colors into frequencies composed of silicon photodiode configurations and current to frequency converters in a single monolithic CMOS IC component. The output of this sensor is a square wave frequency which is directly proportional to the light intensity (irradiance). Full-scale frequency outputs can be scaled by one of three values set via two input pin controls. Digital input and output directly connect to microcontrollers interface or other logic circuits.

The first test was carried out by calibrating the color sensor data by experimenting three different types of fuel, namely Pertamax, Pertalite and Premium. The data generated is in the form of an average RGB number which shows the difference in color in the fuel.

Table 1. Color Sensor Test Results

\begin{tabular}{llll}
\hline $\begin{array}{c}\text { Type of } \\
\text { Fuel }\end{array}$ & R & G & B \\
\hline Pertamax & 35 & 86 & 115 \\
Pertalite & 30 & 90 & 126 \\
Premium & 38 & 100 & 85 \\
\hline
\end{tabular}

The RGB sensor test results will be used to identify the type of fuel that enters the tank, so the calculation of price validation can be carried out in more detail.

\subsection{Internet of thing}

Internet of Things (IoT) is a concept that uses the internet as the main infrastructure network to connect certain objects [13]. The IoT system can also be interpreted as the internet that connects objects, such as meta data (Bari et al, 2013). Three main components in IoT are (1) hardware which consisting of sensors, (2) storage middleware and complicated tools for data analysis, and (3) data visualization or presentation that can be accessed widely on different platforms [14].

The system block in Figure 2 shows the sequence of steps in how this instrument works. A flow sensor measures the volume of fuel entering the tank and a color sensor (RGB sensor) detect the type of fuel. The data obtained from the sensor input is then displayed on the LCD which will then be sent to the smartphone application via the Internet of Things (IoT) system. If there is a difference, the application will provide feedback in the form of a warning that the amount of fuel entering is not in accordance with the measurement. The programming languages used are $\mathrm{C}$ and $\mathrm{C}++$ languages with Arduino IDE software. 


\section{Instrument design and testing method}

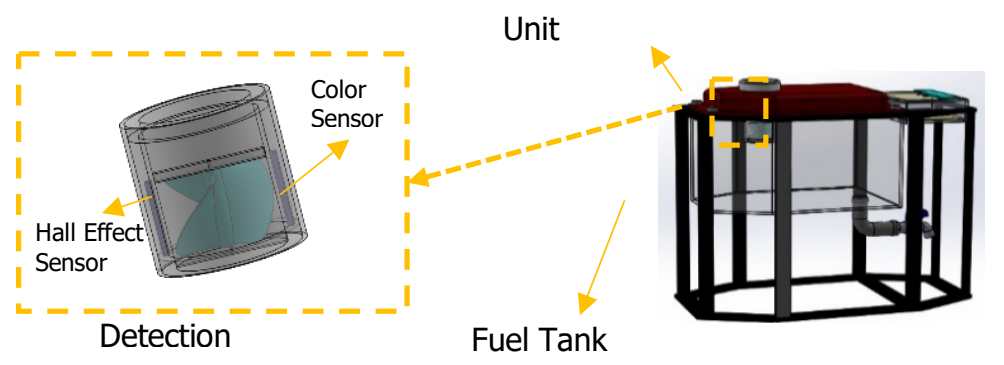

Fig 4. The component of the instrument design

To ensure the accuracy of fuel oil measurements at Semarang oil refueling stations, the Legal Metrology routinely conducts check a stamp at nozzle at least once a year at all gas stations. The process was repeated at each fuel nozzle using a standard 20 liters capacity vessel that had been calibrated by the Directorate of Metrology. Measurements are made at least three times for each nozzle with a tolerance of 100 milliliters per 20 liters. Every nozzle that has been checked and declared valid meets the measurement standards will be given a seal in the form of a mark and sticker which is valid for one year. To test the product prototype, we used the method which applied by Legal Metrology. The fuel used for test is diesel. The data obtained are flowrate (time and volume), calibration factor, multiplier factor, and calculation of inaccurate measurement.

\subsection{Fuel Flow Discharge Measurement}

The provisions regarding fuel oil meters in Indonesia are regulated in the decision of the director general of standardization and consumer protection based on law number 2 of 1981 [15]. Legal Metrology is to protect the public interest through guaranteed measurement accuracy and the existence of order and certainty the law in the use of units of measure, unit standards, methods measurements, and Measuring Instruments, Measuring, Weighing, and Equipment [16].

Testing the flow discharge sensor with legal Metrology by comparing the detected data with the static vessel count. The vessel used is 100 liters with the type of fuel used is diesel fuel. The data obtained are flowrate, calibration factor, multiplier factor, and error value. Figure 5 show the instrument used in the legal metrology technical unit of Semarang City.

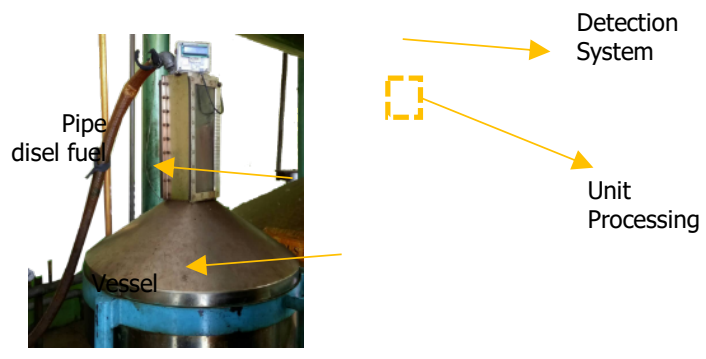

Fig 5. Flow Discharge Measurement Method 
Flow sensors collect data based on axial rotations by turbines on shafts rotation which are then converted into electrical pulses. The faster the turbine rotates, the greater the pulse frequency that is read. The flowrate reading by the sensor uses the formula (1) develop by designer.

$$
\text { Flow }=\frac{\left(\frac{100}{\mathrm{t} 1-\mathrm{t} 0}\right) \times \text { pulse frequency }}{\text { calibration factor }}
$$

The prototype calibration factor is a constant value that is generated in one rotation of the turbine. Whereas the time difference in formula (1) is the start time when the sensor was last used $\left(t_{1}\right)$ and the end time $\left(t_{2}\right)$ of the flow after fuel enters the sensor to stabilize the starting point of the calculation. The flow is the main data that is processed to be converted in units of volume. The formula (1) obtained from the translation of the motion equation of fluid flow through the turbine becomes the main calculation to determine the volume digit value displayed on the LCD or captured in an IoT-based application.

\subsection{Determine the multiplier value}

Tests carried out with the type of diesel fuel. Different fuel type has a different density, so it is necessary to identify the multiplier factor with the repeated testing system to calibrate the prototype. Multiplier factors are identified by repeated testing of at least three tests (based on the Legal Metrology standard) until a stable value is found. The variable input is the flowrate of fuel. To ensure the value is stable, a comparison between the instrument gauge and the vessel is carried out. If the difference from the measurement of the instrument gauge and the vessel is minimal and stable, then the two closest values are taken and the average multiplier will be calculated. The test results are given on Table 2 .

Table 2. Test Result Data for Determining the Ideal Multiplier

\begin{tabular}{|c|c|c|c|}
\hline \multirow{2}{*}{$\begin{array}{l}\text { Multiplier } \\
\text { Factor }\end{array}$} & \multirow{2}{*}{$\begin{array}{c}\text { Debit } \\
\text { (liter / minute) }\end{array}$} & \multicolumn{2}{|c|}{ Volume Measurement Results ( liter ) } \\
\hline & & $\begin{array}{l}\text { Prototype } \\
\text { instrument }\end{array}$ & Vessel \\
\hline 0,698 & 50,36 & 103227 & 99.750 \\
\hline 0,717 & 46,08 & 103228 & 99.950 \\
\hline 0,82 & 41,38 & 91443 & 99.950 \\
\hline 0,75 & 29,50 & 92627 & 99.400 \\
\hline 0,73 & 40,23 & 96159 & 99.350 \\
\hline
\end{tabular}

The multiplier value used is a number that shows the smallest difference between the volume measured by the vessel and the prototype. After knowing several variations of multipliers, an ideal multiplier value analysis is performed using the interpolation method based on two data points that have almost the same constants multiplier factor. The calculation and result of interpolation are given below.

$$
\frac{(\mathrm{X}-0,717)}{(0,73-0,717)}=\frac{(100-103)}{(96-103)}, \text { Then, } \mathbf{X}=0,722571428
$$




\subsection{Calculation of error rate}

The technical requirements of Volumetric Flow Meters is a guideline for officers in carrying out tera and re-volumetric Flow Meters as well as the monitoring of Volumetric Flow Meters, in order to minimize irregularities in the use of Volumetric Flow Meters in fuel oil transactions as well as the realization of measurement measures. The rate of inaccuracy according to Legal Metrology (the government agency responsible for ensuring the measurement of fuel) is the maximum tolerance limit of measuring instruments obtained from the difference in volume calculated using static vessels and tested instrument. According to the Metrology standard, the fuel test uses three variations of flowrate, high $(>65$ liters / minute), moderate (40-64 liters / minute), and low ( $<40$ liters /minute) with three test repetitions for each flow rate.

\section{Result and Discussion}

\subsection{The rate of inaccuracy}

The multiplier coefficient used is 0,722 . The debit under 64 litters per minutes is categorized as medium debit (in green colour in the table 3 ) and debit above 64 categorized as high debit based on Metrology standard. The test results show that the prototype of measuring instrument can detect stable on average flow rates (below 65 liters / minute) with an average flow rate of 56 liters / minute being tested. In addition, the rate of inaccuracy or error has an average of $0.094 \%$ of 100 liters.

Table 3. The results of error calculation

\begin{tabular}{cccc}
\hline \multirow{2}{*}{$\begin{array}{l}\text { Debit } \\
(\mathbf{~ l / m )}\end{array}$} & \multicolumn{2}{c}{ Result Volume (l) } & $\begin{array}{c}\text { Error } \\
\text { percentages }\end{array}$ \\
\cline { 2 - 3 } & Prototype & Vessel & 1,15 \\
84,59 & 100.662 & 99.500 & 2,57 \\
69,95 & 102.128 & 99.500 & 3,88 \\
65,52 & 103.519 & 99.500 & 0,133 \\
63,26 & 99817 & 99950 & 0,065 \\
60,13 & 99585 & 99650 & 0,086 \\
62,79 & 99764 & 99850 & \\
\hline
\end{tabular}

Testing by differentiating the flowrate is done to equate with the fuel filling conditions that occur in general. In real conditions, refueling uses moderate flow rates to ensure stable measurements. The faster the flowrate, the error rate will tend to be greater. Therefore, fuel filling also needs to consider the flowrate factor. Based on the Metrology standard, refueling at moderate flow rates (40-64 liters/minute) will minimize the calculation errors. Based on the results of calculations that have been done, the instrument can work optimally with a moderate flow which can be in accordance with the actual fuel filling conditions. 


\subsection{Testing method of instrument}

There are 3 types of testing that will be carried out on the instrument prototype shows on table 4.

Table 4. Prototype Testing Indicators

\begin{tabular}{|c|c|c|c|}
\hline & Detects fuel type & $\begin{array}{c}\text { Detect the amount of } \\
\text { refueling }\end{array}$ & IOT Process \\
\hline $\bar{E}$ & $\begin{array}{l}\text { Fuel feeding through the } \\
\text { prototype }\end{array}$ & $\begin{array}{l}\text { The fuel passes through the } \\
\text { discharge sensor }\end{array}$ & $\begin{array}{l}\text { Fuel type data and fuel discharge enter } \\
\text { thing-speak. }\end{array}$ \\
\hline 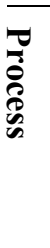 & $\begin{array}{l}\text { The color sensor takes } \\
\text { the RGB value of each } \\
\text { fuel and then is } \\
\text { processed on the } \\
\text { microcontroller }\end{array}$ & $\begin{array}{l}\text { The propeller wheel will } \\
\text { calculate the pulse change } \\
\text { time so that the time } \\
\text { obtained will be changed to } \\
\text { the incoming discharge } \\
\text { speed }\end{array}$ & $\begin{array}{l}\text { The incoming data is combined into one } \\
\text { data packet that will be sent to the server } \\
\text { data that is sent in the form of the date of } \\
\text { fuel type, as well as the incoming debit } \\
\text { using the protocol. }\end{array}$ \\
\hline$\stackrel{0}{\Xi}$ & $\begin{array}{l}\text { Displays fuel typewriting } \\
\text { on the LCD screen }\end{array}$ & $\begin{array}{l}\text { Displays the incoming fuel } \\
\text { discharge on the LCD }\end{array}$ & $\begin{array}{l}\text { The application can retrieve data from } \\
\text { thing-speak and then the data package } \\
\text { received will be shared and displayed } \\
\text { according to the type of type in the } \\
\text { application }\end{array}$ \\
\hline $\begin{array}{l}\Omega \\
\stackrel{\Xi}{\Xi} \\
\stackrel{\Xi}{\Xi}\end{array}$ & Complement & $\begin{array}{l}\text { Permissible error number } \\
0,094 \%\end{array}$ & Complement \\
\hline
\end{tabular}

\subsection{Instrument Measurement Result Report}

The application can be run and divided into four main features, namely general guidance, validation, call centers, and current fuel price infographics. The data detected by the sensor and processed by a microcontroller can be sent to an Android-based application. The following is a documentation of the use of the application. 


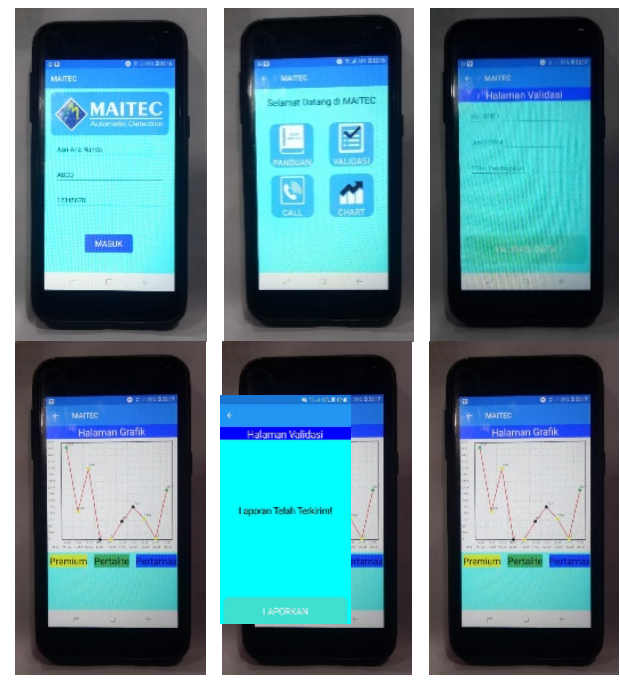

Fig 2. Display of the result report Applications

The process of sending data from the sensor to the application is done through an Arduino microcontroller where there is a program to activate the monitoring system which is then forwarded by the SIM800L module using the GPRS network. SIM800L GSM / GPRS module functions to send data by using the HTTP (Hypertext Transfer Protocol) method through the Application Programming Interface (API) protocol from the microcontroller to the thing-speak server. The use of the GET API command from the thing-speak server in the process of sending data is done, so that data communication can be done with the Application. The application then can read data from thing-speak server using same method. Application used API address to read data using GET API command a display it into application interface.

\section{Conclusion}

There are three function which must be done by the instrument, check the fuel type by color sensor, check the volume discharge by flow rate sensor, and smartphone application that display the measurement result. The Design of testing Method of Fuels Filling Measurement Instrument concluded that the testing method can prove that the instrument prototype is able to detect fuel filling frauds through the detection of color sensors and flow discharges by distinguishing three different types of fuel, Pertamax, Pertalite and Premium. The discharge sensor of the prototype can be used as a dynamic measurement with an error rate of $0.094 \%$ on moderate flowrate of fuel or debit under 64 litters per minutes.

Android-based applications via smartphones can be operated for data validation as well as automatic reporting. Suggestion for further research are considering the results of the color sensor test (RGB Sensor) can be developed to identify other types of fuel. Design also can be directed to consider the usability aspect to increase easy of use of the products especially in reading the display of the application. Read the information are easier in a good display design and will increase user satisfaction ([18-19]).

\section{Acknowledgments}

Authors wishing to acknowledge assistance or encouragement from colleagues of Industrial Engineering Department and special work by student team of Student Creativity Program PKM and 
National student scientific competition or PIMNAS 2019. This research was financially supported by LPPM (Research and community Service) of Diponegoro University in RPP - Riset Pengembangan dan Penerapan scheme 2020.

\section{References}

[1]. Patel R, Pungalia H, Mahajan S, Flow Meter and Arduino Based Fuel Gauge for Automotive Vehicles, OSR Journal of Mechanical and Civil Engineering (IOSRJMCE) Volume 13, Issue 5 Ver. VII (2016)

[2]. BPS, Census Data, Development of the Number of Motorized Vehicles by Type, 19492018, www.bps.go.id (2020)

[3]. Ulrich K T. and Eppinger S D. 1995 Product design and development, McGraw-Hill

[4]. A Farkhan. R, Purwaningsih. A A, Nanda. A. D Suryaningsih, International Journal of Scientific Engineering and Science, Volume 3, Issue 7, pp. 15-19 (2019)

[5]. Mardani. Pillar Of Physics. 2 (8): 4 (2016)

[6]. Azhari .A dan Soeharwinto Jurnal Singuda Ensikom. 13 (36): 89-95 (2015)

[7]. Suhadi, Ramdani, T. Y Rahmad. Jurnal gerbang, volume 9 No. 1 (2019)

[8]. Kumar J. Vinoth 2017 International Journal of Latest Research in Engineering and Technology (IJLRET)ISSN: 2454-5031 Volume 03 -Issue 11

[9]. Divakar Vinay 2014 International Journal of Advanced Research in Computer Engineering \& Technology (IJARCET) Volume 3 Issue 1, January 2014

[10]. G.M.D Putra Jurnal Teknotan Vol. 12 No. 1 (2018)

[11]. Nguyen Trong T, Nguyen T Thang, Nguyen Van T, Cao CC and Jun Hua IOP Conf. Series: Earth and Environmental Science 252 (2019) 022130

[12]. Junaidi, Prabowo Y. D 2018 Project Sistem Kendali Elektronik Berbasis Arduino Anugrah Utama Raharja

[13]. D. Miorandi. S Sicari. F.Pellegrini. I Chlamtac. Ad Hoc Network 10. 14971516 (2012)

[14]. N Bari. G Mani. S.Y Berkovich. The Institute of Electrical and Electronics Engineers (IEEE) Journals 4 (1): 37-39 (2013)

[15]. L. Atzori. M. Giacomo. Elsevier: Computer Networks (2010)

[16]. Ministry of trade Republic Indonesia, Decision of the director general of standardization and consumer protection No 134, (2015)

[17]. Republic Indonesia, Law number 2 of 1981, Legal Metrology

[18]. Purwaningsih R., Yenifi I. 2015 Usability Assessment Of International Office Website of Diponegoro University with Scenario - Based Usability Evaluation Method and WAMMI Method COMTECH Vol 6 No 3 September 2015

[19]. Ratna, P., Heru, P., \& Anggita, H. P. (2018). Usability measurement of telecommunications testing website PT. Telkom Indonesia using user centered design. In E3S Web of Conferences (Vol. 73). EDP Sciences 